\title{
BMJ
}

\section{Evaluation of Talking Parents, Healthy Teens, a new worksite based parenting programme to promote parent-adolescent communication about sexual health: randomised controlled trial}

\author{
Mark A Schuster, chief of general paediatrics and vice chair for health policy research, ${ }^{1,2,4}$ Rosalie Corona, \\ assistant professor, ${ }^{3,4}$ Marc N Elliott, senior statistician, ${ }^{2,4}$ David E Kanouse, senior behavioural scientist, 2,4 \\ Karen L Eastman, research affiliate, ${ }^{4}$ Annie J Zhou, associate quantitative analyst , ${ }^{2,4}$ David J Klein, full \\ quantitative analyst 2,4
}

\begin{abstract}
${ }^{1}$ Children's Hospital Boston and Harvard Medical School, Boston, MA 02115, USA

${ }^{2}$ RAND, Santa Monica, CA 90407

${ }^{3}$ Department of Psychology,

Virginia Commonwealth

University, Richmond, VA 23284

${ }^{4}$ UCLA/RAND Center for

Adolescent Health Promotion,

University of California, Los

Angeles, CA 90095

Correspondence to: M A Schuster, Children's Hospital Boston, 300

Longwood Ave, Boston, MA 02115

mark.schuster@childrens.harvard. edu
\end{abstract}

Cite this as: $B M J$ 2008;337:a308 doi:10.1136/bmj.39609.657581.25

\section{ABSTRACT}

Objective To evaluate a worksite based parenting programme-Talking Parents, Healthy Teens-designed to help parents learn to address sexual health with their adolescent children.

Design Randomised controlled trial (April 2002-December 2005).

Setting 13 worksites in southern California.

Participants 569 parents completed baseline surveys at work, gave permission for confidential surveys to be posted to their adolescent children, and were randomised to intervention or control groups. Parents and adolescents completed follow-up surveys at one week, three months, and nine months after the programme.

InterventionTalking Parents, Healthy Teens consists of eight weekly one hour sessions at worksites for parents of adolescent children in 6th-10th grade (about ages 11-16 years).

Main outcome measures Parent-adolescent communication about a list of sexual topics; whether parent taught adolescent how to use a condom; ability to communicate with parent/adolescent about sex; openness of parent-adolescent communication about sex.

Results Differences between intervention and control groups were significant for the mean number of new sexual topics that parents and adolescents reported discussing between baseline and each follow-up ( $P<0.001$ for each); intervention parents were less likely than controls to discuss no new topics ( $8 \%$ v $29 \%, 95 \%$ confidence interval for difference $16 \%$ to $24 \%$ ) and more likely to discuss seven or more new topics (38\% v $8 \%, 19 \%$ to $41 \%$ ) at nine months. Some differences increased after completion of the programme: at one week after the programme, $18 \%$ of adolescents in the intervention group and $3 \%$ in the control group (6\% to $30 \%$ ) said that their parents had reviewed how to use a condom since baseline ( $P<0.001)$; this grew to $29 \%$ v $5 \%$ (13\% to $36 \%$ ) at nine months ( $\mathrm{P}$ 0.001). Compared with controls at nine months, parents and adolescents in the intervention group reported greater ability to communicate with each other about sex ( $\mathrm{P}$ <0.001) and more openness in communication about sex ( $\mathrm{P}<0.001)$.

Conclusions A worksite based programme can have substantial effects on communication between parents and adolescents about sexual health.

Trial registration Clinical Trials NCT00465010.

\section{INTRODUCTION}

Promoting healthy sexual development during adolescence has been a subject of great controversy in the United States and other countries. ${ }^{1-4}$ An area of common ground is the shared belief that adolescents would benefit from parents playing a larger role in educating them about sexual matters. ${ }^{5-8}$ This belief is supported by research showing that parents can significantly influence adolescents' sexual health and risk reduction through parent-child relationships, parenting practices, and communication about sexual matters. ${ }^{9-11}$ Recent studies have found that adolescents whose parents talk to them about sexuality are more likely to delay intercourse, use contraception, and have fewer partners. ${ }^{12-15}$ Thus, parents might be in a unique position to promote healthy adolescent sexual development. They can talk about sexual behaviours and decision making early and repeatedly; they generally have a distinct emotional bond with ${ }^{16}$ and influence over their children ${ }^{616}$; and they can tailor conversations to children's cognitive, social, emotional, and physical development and needs. ${ }^{17}$

Yet, many parents do not talk to adolescents, particularly younger adolescents, about sexual topics. ${ }^{18}$ Parents report feeling embarrassed, ${ }^{19}$ inadequately informed, ${ }^{19}$ and unsure of what to say or how to begin. ${ }^{20}$ Parents who feel more confident in their ability to communicate with adolescents are more likely to engage in conversations about sex. ${ }^{1819}$ Programmes that increase parents' comfort and communication 
skills related to sexual matters have the potential to change adolescent behaviour.

Efforts to teach parents to communicate about sexual health include incorporating parent activities in youth programmes (such as joint parent-child homework), ${ }^{521}$ teaching adolescents and parents together, ${ }^{522}$ and working with parents alone. ${ }^{5112324}$ A serious challenge for programmes is reaching and engaging parents. ${ }^{25}$ Programmes in community settings (such as schools) are impractical for many parents, especially employed parents, because of scheduling and location issues; participation rates might be low, and dropout rates might be high.

A promising but untested approach is to bring the intervention to parents where they work. ${ }^{26}$ In 2006 , $87 \%$ of $11-16$ year olds in the US lived with one or more employed parents and $76 \%$ of parents living with their adolescents were employed..$^{27}$ Worksite based health promotion has successfully changed health related behaviours in adults, ${ }^{28}$ but few programmes are designed for parents of adolescents-and still fewer for parents who want help in addressing sexual concerns. ${ }^{26}$

We developed Talking Parents, Healthy Teens, a theory based worksite parenting programme to help parents

Sex related discussion topics from parent and adolescent surveys

How girls' bodies change physically as they grow up

How boys' bodies change physically as they grow up

Menstruation (having menstrual periods)

Wet dreams (parents and boys only)

How women get pregnant and have babies

Masturbation (parents only)

What qualities are important in choosing close friends

How to ask someone out on a date

How [you/your child] will make decisions about whether or not to have sex

What it feels like to have sex

Homosexuality/people being gay

Consequences of getting pregnant/getting someone pregnant

How well birth control can prevent pregnancy

How well condoms can prevent sexually transmitted diseases (STDs)

How to choose a method of birth control

How to use a condom

How people can prevent getting sexually transmitted diseases (STDs)

Symptoms of sexually transmitted diseases (STDs)

What to do if a partner doesn't want to use a condom

The importance of not pressurising other people to have sex

Reasons why people like to have sex

Reasons why [you/your child] should not have sex

How [you/your child] will know if [you/he/she] is in love

How to say no if someone wants to have sex and [you/your child don't/doesn't] want to

Some items were omitted for adolescents based on feedback during the formative phase of the study: 24 items were asked of parents, 23 of boys, and 22 of girls. Results change little if analyses of parents' responses were limited to the 22 topics asked of both boys and girls or if all 23 topics are included for boys. become more comfortable and skilled at communicating with adolescents about sexual health. A detailed description of the programme appears elsewhere. ${ }^{29} \mathrm{We}$ report findings on parent-child communication from four time points in a randomised controlled trial. We hypothesised that parents in the programme-and their adolescents - would report more sexual topics discussed for the first time, more repeat discussions, better ability to communicate, and more open communication.

\section{METHODS}

Intervention

Talking Parents, Healthy Teens provides eight weekly one hour sessions to groups of about 15 parents of children in 6th-10th grade (about ages 11-16) at their worksite during the lunch hour (with free lunch). It is a standardised prevention programme guided by a detailed manual. The programme uses roleplay, videotaped interactions, games, and discussions to help parents communicate with children about sex related topics; teach their children communication, assertiveness, and decision making skills; and better supervise and interact with their children. Home assignments strengthen parent-child relationships, and handouts review programme content and sexual health topics. Formative qualitative research ${ }^{2026}$ and three pilot tests informed programme development.

A description of the curriculum can be found elsewhere ${ }^{29}$ but as an example, in one session, parents learn a communication approach called active listening. They learn how to pay attention to what their child is trying to say or convey, listen without interrupting, restate in their own words what they have heard their child say (to confirm that they understood correctly and to show that they were listening), and identify the feelings their child is expressing. Active listening shows adolescents that parents are interested, encourages them to express themselves, and helps them to identify their own thoughts and feelings. In another session, parents are introduced to strategies for initiating conversations about sex because they often find getting started to be a particular challenge. For example, parents are taught to use teaching moments (that is, everyday situations, such as watching a romantic scene in a film, that provide opportunities to start discussions); they are also taught to identify "roadblocks" (such as what a child says to make it hard to talk about sex) and strategies to overcome them.

Each group was led by a facilitator and assistant with experience in adolescent health promotion and 16 hours of specific training. To measure the facilitator's fidelity to the manual, two observers independently reviewed videotaped sessions using a 213 item checklist. They reported $92 \%$ coverage of items on average $(\kappa=0.87)$.

\section{Study design}

We conducted a randomised controlled trial, with randomisation at the individual parent level. Parents were eligible if they were employed at the worksite, had 
Parents who inquired about possible participation in programme $(n=796)$

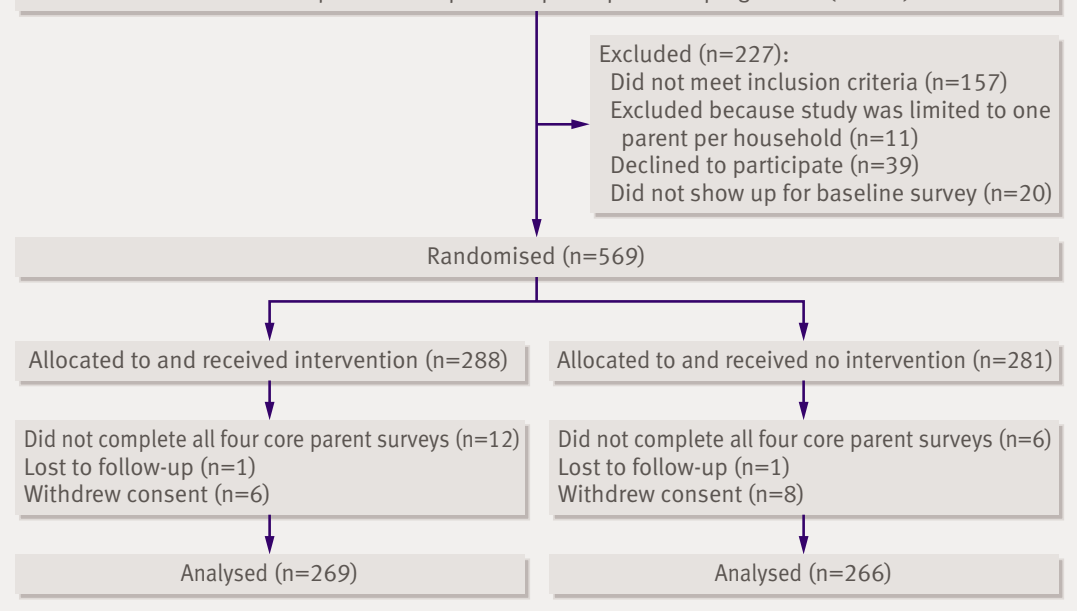

Fig 1 | Flow of participants through trial

at least one child in the relevant grades in school living in the household (at least two days a week), and expected to miss no more than one session. They were recruited from 13 large public and private (for profit and non-profit) worksites in southern California through worksite email, newsletters, etc. Parents completed self administered surveys at work and provided permission for all eligible children in the household to receive posted surveys (including postage paid envelopes). Participants received $\$ 20$ (£10,€13) gift cards for each completed survey. Sites were staggered over time, with data collection from April 2002 to December 2005.

Parents completed baseline surveys a month before the programme; adolescents also completed their surveys before the programme; and both completed follow-up surveys at one week, three months, and nine months after the programme. At each follow-up, parents completed general surveys with questions about themselves and about their child or children as a group; they also completed specific surveys for each eligible child. Surveys for adolescents were specific to their sex and the sex of their participating parent.

After we collected baseline data, parents within each worksite were simultaneously randomised (with computer generated random numbers implemented by an off site programmer) into intervention or control groups within eight strata (factorial combinations of three dichotomous parent characteristics: sex, managerial or professional job status, above or below the baseline median number of sexual topics discussed with adolescents). Randomisation was therefore unknown to participants until after both recruitment and the collection of baseline data; project coordinators informed enrolled participants of their assignments to intervention or control groups.

\section{Response rates}

Parents' response rates at each follow-up (one week, three months, and nine months after the programme) were 97\%, 97\%, and 95\%; 94\% $(\mathrm{n}=535)$ returned all four surveys. For adolescents, $96 \%$ participated, and of them, response rates were $97 \%, 97 \%$, and $94 \% ; 92 \%$ $(\mathrm{n}=627)$ returned all four surveys.

\section{Outcome variables}

Dependent variables were measured at each follow-up. All were ordinal or count variables, except for condom teaching (dichotomous). For the first two variables below (discussions and condom instruction), retrospective time frames were "ever" at baseline and the time period between each follow-up.

Discussions_For each adolescent, parents reported whether they had discussed 24 sex related topics (box). We analysed 22 topics reported by adolescents. For parents/adolescents, we summed baseline responses. At each follow-up, we calculated the number of new topics discussed for the first time between the previous and current follow-up and the number of previously discussed topics repeated during that period.

Condom instruction -Adolescents responded yes/no to "My [mother/father] has reviewed the steps of how to use a condom with me." This item appeared in a battery of items about condoms, which were not asked of parents.

Communication ability-Parents and adolescents were asked, "How would you rate your ability to communicate with your [child/mother/father] about sexual topics?" and responded on a seven point response scale from excellent (7) to terrible (1).

Communication openness - We used a 12 item parent scale to assess openness of parent-adolescent communication about sexual topics (such as, "My child [mother/father] and I talk openly and freely about sexual topics") using a four point strongly agree/ strongly disagree scale $(\alpha=0.86)$. We used a similar seven item measure $(\alpha=0.85)$ for adolescents, with higher scores indicating more openness. Scores are expressed as the centile of the overall baseline distribution.

\section{Independent variable}

Our independent variable was intervention status (whether the person was in the intervention or control group).

\section{Sample size}

We expected smaller effects for adolescents than for parents, so sample sizes were chosen to provide $80 \%$ power to detect a $0.20 \mathrm{SD}$ difference between intervention and control adolescents in outcome changes from baseline ( $\alpha=0.05$, two tailed). Assuming 1.25 eligible adolescents per parent $(85 \%$ of whom would complete all four surveys), design effects totalling 1.20 from clustering and weighting, and an outcome correlation of 0.6 within participants from baseline to nine months, we calculated that we needed to enrol a total of 570 parents (with 712 corresponding adolescents). 


\section{Analysis}

Count and ordinal outcomes were modelled with linear regression because results were insensitive to the normal residual assumption. ${ }^{30}$ The dichotomous outcome was modelled with logistic regression.

We tested the intervention's effectiveness using parent and adolescent reports (separately) with models that predicted an outcome at each follow-up from both intervention status and that outcome's baseline value. Tests of intervention effects analysed participants in

Table 1 | Sample characteristics at baseline* of parents and their adolescent children according to allocation to programme to encourage communication on sexual health (intervention) or control. Figures are numbers (percentages) of participants

\begin{tabular}{|c|c|c|c|}
\hline & Total & Intervention & Control \\
\hline \multicolumn{4}{|l|}{ Parents } \\
\hline No who participated $†$ & 535 & 269 & 266 \\
\hline Women & 385 (72) & 195 (72) & $190(71)$ \\
\hline Men & $150(28)$ & $74(28)$ & $76(29)$ \\
\hline \multicolumn{4}{|l|}{ Age (years): } \\
\hline$\leq 34$ & $54(10)$ & $24(9)$ & $30(11)$ \\
\hline $35-44$ & $260(49)$ & $134(50)$ & $126(47)$ \\
\hline $45-54$ & $200(37)$ & $102(38)$ & $98(37)$ \\
\hline$\geq 55$ & $21(4)$ & $9(3)$ & $12(5)$ \\
\hline \multicolumn{4}{|l|}{ Education: } \\
\hline Graduated from high school or less & $27(5)$ & $7(3)$ & $20(8)$ \\
\hline Two years of college or some college & $207(39)$ & $98(36)$ & $109(41)$ \\
\hline Graduated from four years of college & $114(21)$ & $70(26)$ & $44(17)$ \\
\hline $\begin{array}{l}\text { Attended or completed graduate/ } \\
\text { professional school }\end{array}$ & $187(35)$ & $94(35)$ & $93(35)$ \\
\hline \multicolumn{4}{|l|}{ Race/ethnicity: } \\
\hline African-American & $93(17)$ & $47(17)$ & $46(17)$ \\
\hline Asian or Pacific Islander & $77(14)$ & $42(16)$ & $35(13)$ \\
\hline Latino & $85(16)$ & $34(13)$ & $51(19)$ \\
\hline White & $254(47)$ & $134(50)$ & $120(45)$ \\
\hline Other & $26(5)$ & $12(4)$ & $14(5)$ \\
\hline \multicolumn{4}{|l|}{ Supervisor at work: } \\
\hline Yes & $170(32)$ & $83(31)$ & $87(33)$ \\
\hline No & $365(68)$ & $186(69)$ & $179(67)$ \\
\hline \multicolumn{4}{|l|}{ Household income: } \\
\hline$\leq \$ 49999$ & 77 (14) & $33(12)$ & $44(17)$ \\
\hline$\$ 50000-\$ 89999$ & $149(28)$ & $81(30)$ & $68(26)$ \\
\hline$\$ 90000-\$ 124999$ & $145(27)$ & $71(26)$ & $74(28)$ \\
\hline$\geq \$ 125000$ & $164(31)$ & $84(31)$ & $80(30)$ \\
\hline \multicolumn{4}{|l|}{ Adolescents } \\
\hline No who participated $\dagger$ & 627 & 315 & 312 \\
\hline Female & $321(51)$ & $160(51)$ & $161(52)$ \\
\hline Male & $306(49)$ & $155(49)$ & $151(48)$ \\
\hline \multicolumn{4}{|l|}{ Age (years): } \\
\hline 10 & $21(3)$ & $8(3)$ & $13(4)$ \\
\hline 11 & $129(21)$ & $64(20)$ & $65(21)$ \\
\hline 12 & $127(20)$ & $66(21)$ & $61(20)$ \\
\hline 13 & $137(22)$ & $67(21)$ & $70(22)$ \\
\hline 14 & $107(17)$ & $50(16)$ & $57(18)$ \\
\hline 15 & $82(13)$ & $48(15)$ & $34(11)$ \\
\hline$\geq 16$ & $24(4)$ & $12(4)$ & $12(4)$ \\
\hline
\end{tabular}

${ }^{*}$ No significant differences in baseline demographic data between groups (P>0.05).

†No of parents who filled out self report core surveys and No of adolescents who filled out self report surveys at all four follow-ups. their original randomised group, regardless of attendance; participants who completed all four surveys were weighted to represent all those randomised into intervention and control groups.

We assessed the extent to which any increase in discussions in the control group might be a function of being surveyed or of a change in the environment, rather than just being due to maturation. Specifically, we compared the cross sectional difference in the number of topics ever discussed at baseline associated with one year of age to the average longitudinal change in the year after baseline (that is, from baseline to the fourth survey) within the control group.

This trial produced unbiased estimates without covariates. Because our stratified randomisation produced a well balanced design, secondary analyses not reported here found that a set of eight covariates had minimal effect on the estimate or precision of the intervention coefficient.

Our population of interest was eligible parents who completed the baseline survey (and were therefore randomised) and their eligible adolescents. We therefore modelled non-participation of adolescents at baseline and parent and adolescent participation in follow-up surveys. We created two sets of inverse probability attrition weights, corresponding to all parent and adolescent surveys completed at each time. We predicted attrition through multivariate logistic regression using baseline measures (demographics, communication before intervention). Parent attrition was related to race/ethnicity; adolescent attrition was related to sex.

The unit of analysis was the adolescent. Analyses accounted for clustering of adolescents within parents (that is, dependence among adolescent observations induced by sampling adolescents through their parents) with a "sandwich" estimator and for attrition weights with linearisation. Because rates of missing data across items were low (mean 1.1\%), we used a single Markov chain Monte Carlo imputation from PROC MI (SAS 9.1).

\section{RESULTS \\ Participants}

We received inquiries about possible participation in the programme and the study from 796 parents. We excluded 227 who did not meet inclusion criteria, who could not participate because the study was limited to one parent per household, who declined to participate, or who did not show up to complete their baseline survey (fig 1). We did not know the number of eligible employees at each worksite because employers did not have information available on the ages of children in employee households. We randomised 569 parents who completed the baseline survey, 288 to the intervention group and 281 to the control group. There were no significant differences between the groups (table 1). Participating intervention and control parents had 710 eligible adolescents (683 adolescents participated and completed baseline surveys). 

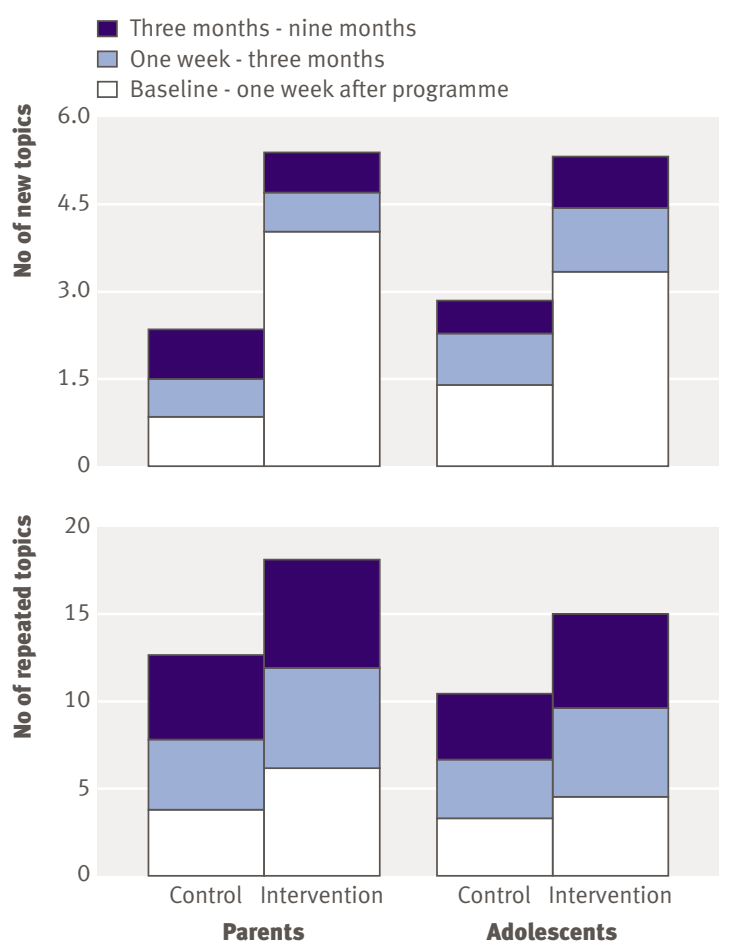

Fig 2 | New (top) and repeated (bottom) sexual topics discussed, reported by parents and adolescents. Cumulative difference between intervention and control from baseline to each subsequent survey was significant at P<0.001. For new topics, interval differences were not significant. For repeated topics, interval difference for parents was $P<0.001$ at three months and $\mathrm{P}=0.003$ at nine months; for adolescents, difference was P $<0.001$ for each interval

Parents attended a median of seven sessions. One week after the programme, 20\% of control parents reported talking with intervention parents about the programme or seeing or reading the programme's educational materials.

\section{New topics}

At baseline, parents on average reported having ever discussed 8.9 of 24 topics (SD 5.5) with their adolescents; adolescents reported 7.2 of 22 topics (SD 5.3). Between baseline and one week after the programme, intervention parents reported discussing more new topics with their adolescents than control parents (mean $4.0 v 0.8,95 \%$ confidence interval of the difference 2.7 to $3.6 ; \mathrm{P}<0.001)$. This difference persisted at a similar magnitude and significance for newly incident discussions at three and nine months after the programme (fig 2). Adolescents in the intervention group reported 1.9 more new topics from baseline to one week after the programme than control adolescents (mean $3.3 v 1.4,95 \%$ confidence interval for difference 1.4 to $2.5 ; \mathrm{P}<0.001)$. This difference persisted at three and nine months.

There was a large difference between the intervention and control groups for parents in the mean number of new topics discussed since baseline $(\mathrm{P}<0.001)$ (table 2): intervention parents were much less likely than control parents to discuss no new topics $(8 \%$ v $29 \%, 16 \%$ to $24 \%)$ and much more likely to discuss seven or more new topics (38\% v 8\%, 19\% to $41 \%$ ). Similarly, $33 \%$ of adolescents in the intervention group and $13 \%$ in the control group (12\% to $30 \%)$ reported seven or more new topics $(\mathrm{P}<0.001)$.

At baseline, each additional year of age was associated with 0.7 extra topics ever discussed in parents' reports $(\mathrm{P}<0.001)$ and a non-significant estimate of 0.2 extra topics ever discussed in adolescents' reports $(\mathrm{P}=0.20)$. In contrast, parents in the control group reported having ever discussed 2.7 more topics at the nine month follow-up (one year after baseline) than they had at baseline, with control adolescents reporting an increase of 2.8 topics ( $\mathrm{P}<0.001$ for each).

\section{Repeated topics}

On average, intervention parents repeated 2.7 more topics than controls (6.4 v3.7, 2.1 to $3.2 ; \mathrm{P}<0.001)$ one week after the programme. The difference grew through the three $(\mathrm{P}<0.001)$ and nine month $(\mathrm{P}=0.003)$ follow-up surveys (fig 2). Adolescents in the intervention group repeated 1.2 more topics than controls (4.5 v 3.3, 0.7 to $1.6 ; \mathrm{P}<0.001)$; their differences also grew through subsequent follow-up surveys $(\mathrm{P}<0.001$ at both three and nine months).

\section{Condom teaching}

At baseline, 4\% of adolescents reported that their parent had reviewed how to use a condom. One week after the programme, more adolescents in the intervention than in the control group reported receiving this instruction since baseline $(18 \%$ v $3 \%, 6 \%$ to $30 \%$; $\mathrm{P}<0.001)$. The difference between the groups grew by nine months $(29 \%$ v $5 \%, 13 \%$ to $36 \% ; \mathrm{P}<0.001)$ (fig 3 ).

\section{Communication ability}

At baseline parents rated their ability to discuss sexual topics with their adolescent as between "fair" and "good" (mean 4.6, SD 1.3) on average. Although control parents showed no significant change, intervention parents showed an increase from baseline relative to controls that remained significant throughout $(\mathrm{P}<0.001$ at each follow-up) (fig 4$)$.

Adolescents rated their baseline ability to discuss sexual topics with their parents as "fair" (mean 4.2, SD 1.8). Reported ability in adolescents in the control group declined over the follow-up surveys $(\mathrm{P}<0.001$, linear trend test). The cross sectional effect of age at baseline (dropping 0.24 units a year, $\mathrm{P}=0.001$ ) did not significantly differ in magnitude from the longitudinal decline among controls over follow-up surveys, which is consistent with the longitudinal decline being a pure maturation effect (that is, the adolescents growing older) rather than a repeated survey effect.

Adolescents in the intervention group significantly differed from those in the control group in their ability to communicate about sexual topics at three months (mean $4.3 v 4.0,0.1$ to $0.5 ; \mathrm{P}=0.02$ ). At nine months, the 
decline in the control group was not evident in the intervention group, with a significant difference between the two $(\mathrm{P}<0.001)$.

\section{Communication openness}

After the programme, parents in the intervention group reported significantly higher scores on a scale measuring openness of communication about sexual matters, compared with their scores at baseline $(\mathrm{P}<0.001$ at each follow-up) and with scores in the control group $(\mathrm{P}<0.001$ at each follow-up). Scores on the openness of communication scale in adolescents in the control group declined from baseline ( $\mathrm{P}=0.006$ at nine months), whereas scores for the intervention group improved compared with baseline $(\mathrm{P}=0.005)$, with higher scores at each follow-up $(\mathrm{P}<0.001$ for each) (fig 4$)$.

\section{DISCUSSION}

This randomised controlled trial of a workplace programme showed that parents can successfully be helped to communicate with their adolescent children about sexual health. Parents have many reasons for not being actively involved in their children's sex education-for example, they may feel embarrassed about the topics, uninformed about the facts, or unsure of how and at what age to address various issues. ${ }^{1920}$ Research suggests, however, that parents can strongly influence adolescents' sexual development and sexual health and risk behaviours. ${ }^{6}$ Therefore it is important to determine whether teaching parents to communicate with adolescents can effectively harness parental influence to promote adolescent health.

\section{The programme}

Talking Parents, Healthy Teens is a worksite based programme that applies the principles of worksite health promotion to help parents learn to communicate with adolescents about sexual health and risk reduction. ${ }^{29}$ It is unique in being offered at parents' worksites during lunch hour, which we believed could

\begin{tabular}{|c|c|c|}
\hline No of new topics & Control & Intervention* \\
\hline \multicolumn{3}{|c|}{ Reported by parents: } \\
\hline 0 & $29(24$ to 34$)$ & $8(5$ to 11$)$ \\
\hline 1 & 20 (15 to 24$)$ & 11 (7 to 14$)$ \\
\hline 2 & 16 (12 to 21$)$ & 10 (7 to 13$)$ \\
\hline $3-6$ & 27 (21 to 32 ) & 33 (28 to 38$)$ \\
\hline$\geq 7$ & $8(5$ to 12$)$ & 38 (32 to 44$)$ \\
\hline \multicolumn{3}{|c|}{ Reported by adolescents: } \\
\hline 0 & 31 (26 to 36$)$ & 18 (14 to 22$)$ \\
\hline 1 & 19 (15 to 24$)$ & 11 (8 to 15$)$ \\
\hline 2 & 9 (6 to 12$)$ & $8(5$ to 10$)$ \\
\hline $3-6$ & 28 (23 to 33 ) & 30 (24 to 35$)$ \\
\hline$\geq 7$ & 13 (9 to 17$)$ & 33 (28 to 39$)$ \\
\hline
\end{tabular}

*Intervention group discussed significantly more topics than control group ( $\mathrm{P}<0.001)$ in linear regressions, predicting uncollapsed count of new topics discussed after baseline and adjusted for number of topics discussed at baseline. Separate models run for parents and adolescents.

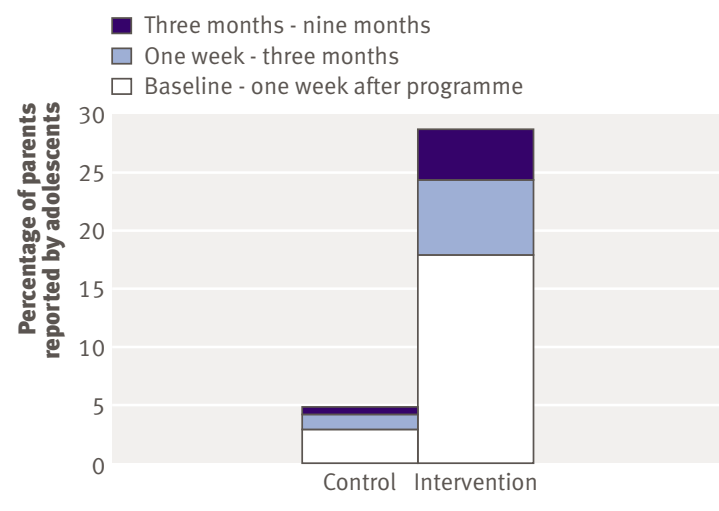

Fig 3 | Parents who reviewed steps of how to use a condom, as reported by adolescents. (My mother [father] has reviewed the steps of how to use a condom with me (yes/no)). Adolescents who reported at baseline that their mother or father had reviewed steps of putting on condom were excluded $(1.3 \%$ of intervention adolescents and $1.9 \%$ of control adolescents). Cumulative difference between intervention and control over interval from baseline to each subsequent survey significant at $P<0.001$. Interval difference between each survey was $P=0.006$ for one week after intervention to three months and $\mathrm{P}=0.01$ for three to nine months

increase participation and retention. Unlike many evaluations of parenting programmes, this study used a randomised controlled trial. We investigated the immediate and extended effects of the communication skills we taught, as distinct from pre-existing skills or other characteristics that parents might selectively bring into such a programme.

Reports from both parents and adolescents indicate that the programme had significant immediate effects on parent-adolescent communication. Compared with control parents, intervention parents reported more conversations about new sexual topics and more repeated conversations about topics that they had previously discussed. Both are important. Parents need to overcome the initial hurdle of discussing sexual issues, but they also need to discuss such issues in an ongoing, evolving, and adaptive manner for an enduring impact. ${ }^{183132}$ Reported improvement in adolescents paralleled parents' reports, providing further evidence that parents can learn and implement communication skills. Parents and adolescents in the intervention groups did not subsequently revert back towards the trajectory in the control groups; indeed, the differences between the groups grew over time for parents' reports on repeated talks and adolescents' reports on new and repeated talks.

A particularly dramatic illustration of the programme's impact was with adolescents' reports of whether parents taught them how to use condoms. At baseline, few parents had done this, but at the end of the programme, a large and significant difference between the groups emerged. At three and nine months, the difference not only remained but actually widened, indicating an ongoing influence of the programme on parents' behaviour. Some studies have found that parent-adolescent conversations about condoms are 
associated with adolescents' confidence in using condoms, comfort with talking to partners about condoms, and actual condom use. ${ }^{12-15}$ One reason that the programme presents this material is so that parents, regardless of whether they support condom use and whether they feel comfortable teaching their adolescents about condoms, can answer questions if asked.

Parents and adolescents in the intervention group reported not only more discussions than those in the control group but also a greater ability to talk about sexual matters and more openness discussing sex related topics with one another. These findings were sustained and continued to accumulate for at least nine months after the programme ended. By contrast, adolescents in the control group reported a decline over time for both measures. For communication ability, the intervention stemmed this natural decline, and for openness, the intervention caused absolute improvement. The growing difference between intervention and control is unusual in that most parent focused programmes have found effects only just after the end of the programme ${ }^{23}$ or within the subsequent three months. ${ }^{24}$ Moreover, this ongoing expansion suggests that parents are not merely conveying static knowledge to adolescents but rather are altering sexual communication dynamics within the family in a way that might increase their effectiveness in promoting adolescent sexual health.

\section{Findings in context}

This study's implications go beyond the substantive areas of parent-adolescent communication and healthy adolescent development. They point to the potential to expand the scope of worksite health promotion beyond employees' own health. Our formative work found that employers showed enthusiasm for programmes that help parents of adolescents. ${ }^{2026}$ In an era with lists of family friendly businesses in Australia, Canada, countries of the European Union, and the US, there is increased attention to ways employers can support parents. Physicians might want to consider worksite health promotion as another means to address behavioural health concerns of patients and families. In addition, we have shown that a randomised controlled trial can be successfully implemented in worksite health promotion research. One concern with such trials, particularly with randomising at the individual level, is that controls can be exposed to programme content. Loss of efficiency from clustering in group randomisation, however, is almost always a greater threat to power to detect intervention effects than from unintended exposure in controls. ${ }^{33}$

Because some control parents reported exposure, our study's substantial findings probably underestimate the true magnitude of the effects of the intervention. It is also possible that those in the control group (as well as the intervention group) were prompted by the survey's list of discussion topics to engage in new or repeat conversations about particular topics, particularly given that these respondents were interested enough in communication to volunteer for the study. If so, the survey itself might constitute a small but important intervention that introduced more than two new topics to parents and adolescents in each study arm beyond what would have been expected from maturation alone, with the programme adding substantial additional benefits, as reported in the primary analyses that compared change within the intervention group with change within the control group.

\section{Limitations}

As with all self reported data, respondents might misreport answers and thereby create bias towards a particular result. Intervention parents might be inclined to report improved communication, but adolescents, who were not in the programme, would have little apparent reason to over-report communication. Our
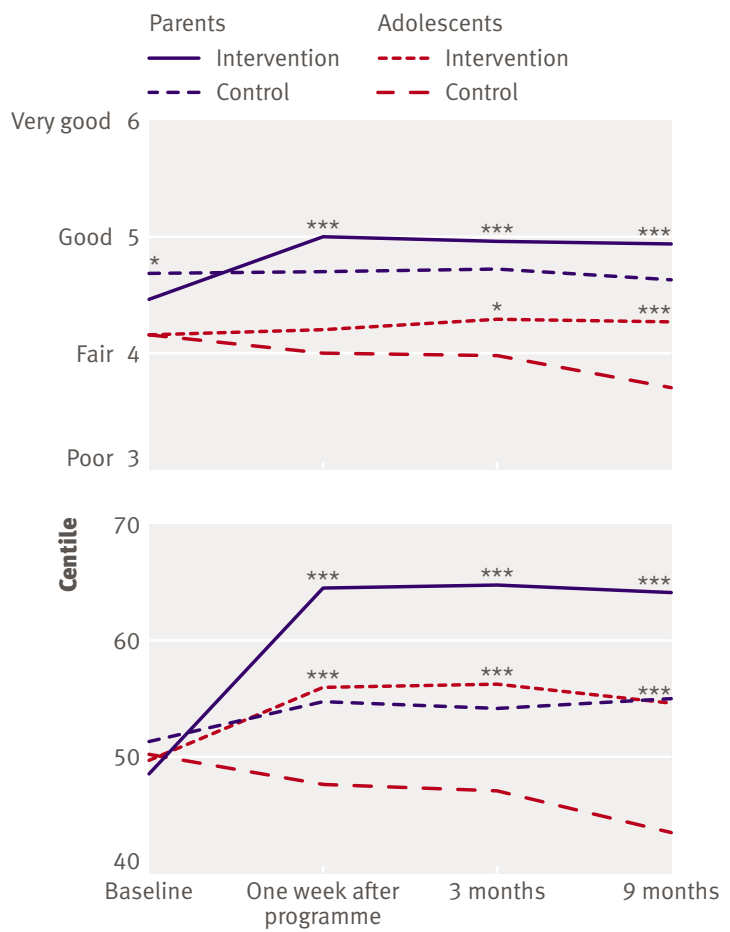

$\overline{\text { Fig } 4 \text { |Top: ability to communicate with adolescent/parent about }}$ sexual topics (How would you rate your ability to communicate with your child [mother/father] about sexual topics? excellent/ very good/good/fair/poor/very poor/terrible). Bottom: openness of parent-adolescent communication scale (12 item scale for parents; 7 item scale for adolescents). Because units of scale have no absolute meaning, we have expressed all scores on this scale as centile of baseline distribution (control and intervention combined) to which they correspond. For example, score of 65 th centile at three month follow-up for intervention group indicates that average intervention participant at three month follow-up had score better than $65 \%$ of participants at baseline. In tests for linear time trend across survey waves, the parent control group does not change significantly over four surveys $(P=0.14)$, while parent intervention group increases significantly $(P=0.001)$; adolescent control group declines significantly over time $(P=0.006)$, while adolescent intervention group increases $(P=0.005)$. ${ }^{*}<<0.05$; ${ }^{* \star *} P<0.001$ for intervention-control comparisons, tested with a linear regression predicting communication at each survey and controlling for communication at baseline 


\section{WHAT IS ALREADY KNOWN ON THIS TOPIC}

Research shows that parents can significantly influence adolescents' sexual health and risk reduction through parent-adolescent relationships, parenting practices, and communication about sexual matters, but few interventions help parents raise sexually healthy youth

Worksite health promotion has been effective for adult health issues but has not been well studied as a way to influence adolescents

\section{WHAT THIS STUDY ADDS}

A worksite based programme for parents of adolescents can have significant immediate and longer term effects on parent-adolescent communication related to sexual health

results might not be generalisable to all employed parents. Although participating worksites covered a broad cross section of large employers, smaller worksites might have different experiences implementing the programme. While our sample was diverse in terms of education, race/ethnicity, and manager/staff rank, incomes tended to be higher than average, consistent in the US with employment at large worksites, which might reduce generalisability to lower income parents at small worksites. Likewise, all the worksites were located in a large metropolitan area in the US; it will be important to test the intervention in various areas to assess its effectiveness in different populations. In addition, the offer of incentives for participation and the programme's implementation as part of a study could have influenced parents' willingness to participate. Some participants might have been attracted by the opportunity to participate in a study and receive monetary incentives, while others might not have volunteered because they were not interested in participating in a study and filling out surveys. Because most of the adolescents were middle school aged and because children of employed parents (who, on average, have higher household incomes) tend to have a later expected age of sexual initiation, ${ }^{34}$ a much longer follow-up period would be necessary to determine whether communication influences sexual behaviours. None the less, we have shown that Talking Parents, Healthy Teens significantly increases and improves parent-adolescent communication, which is not only linked with adolescent sexual health and risk reduction $^{121415}$ but is also a worthy goal in itself.

We thank Rosa-Elena Garcia and the RAND Survey Research Group for data collection; Elaine Quiter, Diane Schoeff, and Katherine Vestal for project coordination; Susan Park and Gillian Smith for research assistance; Kate Sommers-Dawes, Scott Stephenson, and Katherine Woolsey for manuscript assistance; Laura Bogart and Steven Martino of RAND for comments on a draft of the manuscript; the programme's facilitators and assistant facilitators; and other UCLA/RAND Center for Adolescent Health Promotion staff who helped in the development, implementation, and evaluation of the programme. We also thank the centre's community advisory board and scientific advisory board for their guidance, the study worksites for their assistance, and the study participants for sharing their time and experiences

Contributors: All authors made substantial contribution to conception, design, analysis, and interpretation of data. MAS, RC, and MNE drafted the article, and all authors were involved in revising it critically for important intellectual content and final approval. MAS is guarantor.

Funding: Grant R01 MH61202 from the National Institute of Mental Health and cooperative agreements U48/CCU915773 and U48/DP000056 from the Centers for Disease Control and Prevention.
Competing interests: None declared

Ethical approval: The institutional review boards of RAND and the University of California, Los Angeles approved the study protocol. Provenance and peer review: Not commissioned; externally peer reviewed.

1 Inine IM. Talk about sex: battles over sex education in the United States. Berkeley, CA: University of California Press, 2004.

2 Stammers T, Ingham R. For and against: doctors should advise adolescents to abstain from sex. BMJ 2000;321:1520-2.

3 Wellings K, Wilkinson P, Gundy C, Kane R, Lachowycz K, Jacklin P, et al. Teenage pregnancy strategy evaluation final report. London: Teenage Pregnancy Unit, 2005.

4 BBC News. Sex education runs into trouble. http://news.bbc.co.uk/ 1/hi/world/south_asia/6949714.stm.

5 Kirby D, Miller B. Interventions designed to promote parent-teen communication about sexuality. In: Feldman S, Rosenthal D, eds. New directions for child and adolescent development. San Francisco, CA Jossey-Bass, 2002:93-110.

6 Meschke LL, Bartholomae S, Zentall SR. Adolescent sexuality and parent-adolescent processes: promoting healthy teen choices. I Adolesc Health 2002;31:264-79.

7 American Academy of Pediatrics: Committee on Psychosocial Aspects of Child and Family Health and Committee on Adolescence. Sexuality education for children and adolescents. Pediatrics 2001;108:498-502.

8 Ford L. Campaigners renew calls for better sex education. http:// education.guardian.co.uk/sexeducation/story/0,,1491113,00. html.

9 Miller BC, Benson B, Galbraith KA. Family relationships and adolescent pregnancy risk: a research synthesis. Dev Rev 2001;21:1-38.

10 Wight D, Williamson L, Henderson M. Parental influences on young people's sexual behaviour: a longitudinal analysis. J Adolescence 2006;29:473-94.

11 Dittus P, Miller KS, Kotchick BA, Forehand R. Why parents matter!: the conceptual basis for a community-based HIV prevention program for the parents of African American youth. / Child Fam Stud 2004;13:5-20

12 DiClemente RJ, Wingood GM, Crosby R, Cobb BK, Harrington K, Davies SL. Parent-adolescent communication and sexual risk behaviors among African American adolescent females. J Pediatr 2001;139:407-12.

13 Stone N, Ingham R. Factors affecting British teenagers' contraceptive use at first intercourse: the importance of partner communication. Perspect Sex Reprod Health 2002;34:191-7.

14 Hutchinson MK, Jemmott JB, Jemmott LS, Braverman P, Fong GT. The role of mother-daughter sexual risk communication in reducing sexual risk behaviors among urban adolescent females: a prospective study. J Adolesc Health 2003;33:98-107.

15 Dilorio C, Pluhar E, Belcher L. Parent-child communication about sexuality: a review of the literature from 1980-2002. I HIV AIDS Prev Educ Adolesc Child 2003;5:7-32.

16 Lezin N, Rolleri L, Bean S, Taylor J. Parent-child connectedness: implications for research, interventions, and positive impacts on adolescent health care. Santa Cruz, CA: ETR Associates, 2004.

17 Kotchick BA, Shaffer A, Forehand R, Miller KS. Adolescent sexual risk behavior: a multi-system perspective. Clin Psychol Rev 2001;21:493-519.

18 Raffaelli M, Bogenschneider K, Flood MF. Parent-teen communication about sexual topics. J Fam Issues 1998;19:315-33.

19 Jaccard J, Dittus PJ, Gordon VV. Parent-teen communication about premarital sex: factors associated with the extent of communication.) Adolesc Res 2000;15:187-208.

20 Eastman KL, Corona R, Ryan GW, Warsofsky AL, Schuster MA Worksite-based parenting programs to promote healthy adolescent sexual development: a qualitative study of feasibility and potential content. Perspect Sex Reprod Health 2005;37:62-9.

21 Kirby DB, Baumler E, Coyle KK, Basen-Engquist K, Parcel GS, Harrist R, et al. The "Safer Choices" intervention: its impact on the sexual behaviors of different subgroups of high school students. J Adolesc Health 2004:35:442-52.

22 Stanton BF, Li X, Galbraith J, Cornick G, Feigelman S, Kaljee L, et al. Parental underestimates of adolescent risk behavior: a randomized, controlled trial of a parental monitoring intervention. J Adolesc Health 2000;26:18-26

23 Lefkowitz ES, Sigman M, Au TK. Helping mothers discuss sexuality and AIDS with adolescents. Child Dev 2000;71:1383-94.

24 Klein JD, Sabaratnam P, Pazos B, Auerbach MM, Havens CG, Brach MJ. Evaluation of the parents as primary sexuality educators program.J Adolesc Health 2005;37:S94-9.

25 Coatsworth JD, Duncan LG, Pantin H, Szapocznik J. Patterns of retention in a preventive intervention with ethnic minority families. J Prim Prev 2006;27:171-93. 
26 Schuster MA, Eastman KA, Fielding JE, Rotheram-Borus MJ, Breslow L, Franzoi LL, et al. Promoting adolescent health: worksite-based interventions with parents of adolescents. J Public Health Man 2001;7:41-52.

27 US Census Bureau. Annual demographic supplement to the March 2006 current population survey. www.bls.gov/cps/.

28 Chenoweth DH. Worksite health promotion. 2nd ed. Champaign, IL: Human Kinetics, 2007.

29 Eastman K, Corona R, Schuster M. Talking parents, healthy teens: a worksite-based program for parents to promote adolescent sexual health. Prev Chron Dis 2006;3:1-10.

30 Jarque CM, Bera AK. Efficient tests for normality, homoscedasticity and serial independence of regression residuals. Economics Letters 1980;6:255-9.
31 Martino SC, Elliott MN, Corona R, Kanouse DE, Schuster MA. Beyond the "Big Talk": the roles of breadth and repetition in parent-adolescent communication about sexual topics. Pediatrics 2008;121:e612-8.

32 Jaccard J. Parent-child relationships: do parents talk with children about sex? In: Ponzetti JJ, ed. International encyclopedia of marriage and family. 2nd ed. New York, NY: MacMillan Reference USA, 2002:1437-49.

33 Torgerson DJ. Contamination in trials: is cluster randomisation the answer? BMJ 2001;322:355-7.

34 Lammers C, Ireland M, Resnick M, Blum R. Influences on adolescents' decision to postpone onset of sexual intercourse: a survival analysis of virginity among youths aged 13 to 18 years. J Adolesc Health 2000;26:42-8.

Accepted: 2 May 2008 